\author{
Asian Journal of \\ Medical and Biological Research \\ ISSN 2411-4472 (Print) 2412-5571 (Online) \\ www.ebupress.com/journal/ajmbr
}

\title{
Article \\ Quality of hospital services in 5S-KAIZEN-TQM implemented secondary level hospital: a cross-sectional study
}

\author{
Md Abdur Rouf ${ }^{1 *}$, Sumon Chandra Debnath ${ }^{2}$, Md. Ekramul Haque ${ }^{3}$, Zobaid Mohammad Rahat Chowdhury ${ }^{4}$, \\ Dewan Md. Mehedi Hasan ${ }^{5}$, Taslima Zannat ${ }^{6}$ and Md. Fazlay Rabby ${ }^{7}$ \\ ${ }^{1}$ Assistant Director, Aichi Medical College and Hospital, Uttara, Dhaka, Bangladesh \\ ${ }^{2}$ Assistant Research Officer, Bangladesh Breastfeeding Foundation, Mohakhali, Dhaka-1212, Bangladesh \\ ${ }^{3}$ Evaluator (M\&PDC), CDC, DGHS, Mohakhali, Dhaka-1212, Bangladesh \\ ${ }^{4}$ Assisant Director, East West Medical College Hospital, Uttara, Dhaka-1230, Bangladesh \\ ${ }^{5}$ Medical Officer (MBPC), Hospital Service Management, DGHS, Mohakhali, Dhaka-1212, Bangladesh \\ ${ }^{6}$ Medical Officer, NICU, Dhanmondi General and Kidney Hospital, Dhanmondi, Dhaka, Bangladesh \\ ${ }^{7}$ Medical Officer cum Enumerator, Associates for Community and Population Research, Dhaka, Bangladesh \\ *Corresponding author: Md Abdur Rouf, Assistant Director, Aichi Medical College and Hospital, Dhaka, \\ Bangladesh. Phone: +8801713914449; E-mail: rouf52hm@gmail.com
}

Received: 07 September 2017/Accepted: 24 September 2017/ Published: 28 September 2017

\begin{abstract}
This cross-sectional study was conducted with an objective to find out the quality of health care services in 5S-KAIZEN-TQM implemented two secondary level hospital in Bangladesh. The study participants were the service receiver's whose age more than 15 years and those who were attended at 100 bedded Narsingdi General Hospital, Bangladesh. The period of the study extending from January to December 2016. Data were collected from 50 service receivers through face to face interviews using a semi-structured questionnaire. Out of 50 respondents, half $(50.0 \%)$ of the service receiver was $\leq 25$ years in which maximum $(74.0 \%)$ were female. More than half of the respondent's monthly income was less than 20000 taka. In this study, half (50.0\%) of the respondents stated that they were waiting for 15-30 minutes, $60.0 \%$ patients stated that the doctor had concentrated to patients during treatment and more than two-third (68.0\%) of them performed physical examination. A vast majority $(90.0 \%)$ of the patients said that the doctor gave the explanation of prescribed drug. More than three-fourth $(76.0 \%)$ of the respondents replied that they were satisfied on receiving the nursing services and rest of them (24.0\%) were not satisfied. The present study findings stated that less than two-third $(64.0 \%)$ of the respondents said that safety and security system was very good. On the other hand, $64.0 \%$ of the respondents were satisfied about cleanliness of the hospital and $88.0 \%$ had satisfied about ambulance service. Maximum of the respondents (88.0\%) were satisfied on water and sanitation facility and more than half (54.0\%) of the respondents were satisfied on electricity supplies in the hospital. In this study, majority (88.0\%) of the respondents were satisfied on lab investigation facilities and $72.0 \%$ of the respondents were satisfied on drug supply and radiology and imaging services. $5 \mathrm{~S}$ could be applied to health-care facilities regardless of locations. However, the evidence base on its applicability in such settings is limited, and further research is required in this area.
\end{abstract}

Keywords: quality; hospital services; 5S-KAIZEN-TQM, secondary level hospital

\section{Introduction}

The 5S management method where 5S stands for the five Japanese words Seiri, Seiton, Seiso, Seiketsu, and Shitsuke has been used in the automotive and other industries. These five words, often translated into English as "sort, set in order, shine, standardize, and sustain" broadly refer to the discipline of cleanliness in any place (Hirano, 1996; JICA, 2013). 
The 5S management method was originally implemented by manufacturing enterprises in Japan (Hirano, 1995). In Japan, 5S has been commonly practiced at hospitals (Hasegawa, 2006; Takahara, 2010). It has also been recognized as a method for health-care quality improvement in several books published in the USA (Chalice, 2007; Graban, 2011; Kaplan, 2008).

In the context of the health-care quality improvement, $5 \mathrm{~S}$ has often been regarded as one of the "lean" tools (Mazzocato et al., 2010) where lean refers to a set of approaches for continuous improvement that aim to maximize added value by removing all necessary factors that do not generate value (Womack et al., 1990). Lean has been recognized as one of the key quality improvement approaches in health-care (Powell et al., 2008).

The Japan International Cooperation Agency (JICA) has adopted 5S as part of its technical cooperation scheme to improve health-care service quality and has assisted several low- and middle-income countries (JICA, 2013; Honda, 2012).

In some context, the $5 \mathrm{~S}$ approach toward TQM was represented as "5S-KAIZEN-TQM," which was also interchangeably referred to as "5S-CQI-TQM" (MHSW, 2009). To identify additional information pertaining particularly to the context of the $5 \mathrm{~S}$ application and its adoption as part of the Bangladesh government initiatives, we set an objective to find out the quality of health care services in 5S-KAIZEN-TQM implemented two secondary level hospitals in Bangladesh.

\section{Materials and Methods}

\subsection{Study type and area}

This study cross-sectional study was conducted in 5S-KAIZEN implemented 100 bedded Narsingdi District Hospital.

\subsection{Study participants}

The study participants were the service receiver's whose age more than 15 years and those who were attended at 100 bedded Narsingdi General Hospital.

\subsection{Sampling and data collection technique}

The estimated sample size was 50 and service receiver (patients) were selected by convenient sampling. Data composed of five hospital services such as administrative, clinical, nursing, and utility and support services. Data were collected through face to face interviews using a semi-structured questionnaire. Observational checklist was used to identify the hospital service related data.

\subsection{Data processing and analysis}

Data was cleaned for completeness and consistencies, coded and entered in to SPSS version 20 for analysis. The results were organized, summarized and presented using appropriate descriptive measures such as text, tables, graphs, frequencies and percentage.

\subsection{Ethical issues}

Ethical clearance was obtained from Institutional Review Committee of National Institute of Preventive Medicine (NIPSOM). Permission letter was obtained from all selected study health facilities. Informed verbal consent was obtained from each study participant after explaining the aim of the research. Individual participant records were coded on each respective questionnaire and confidentiality was maintained at all levels of the study.

\section{Results}

The sociodemographic profile of the respondents were distributed in Table 1. Out of total 50 respondents, half $(50.0 \%)$ of the service receiver was $\leq 25$ years in which maximum $(74.0 \%)$ were female. Approximately twothird $(66.0 \%)$ of the respondents' were Diploma, HSC and below. More than half of the respondent's monthly income was less than 20000 taka (Table 1).

About $78.0 \%, 76.0 \%, 90.0 \%$ and $40.0 \%$ of the stated that they saw citizen charter, visibility of mission and vision of the hospital, easy access of the reception and problem during registration, respectively (Table 2). 
Table 1. Socio-demographic profile of the service receiver $(n=50)$.

\begin{tabular}{llc}
\hline Characteristics & & Service Receiver $(\mathbf{n}=\mathbf{5 0})$ \\
\hline Age group & $\mathrm{n}$ & $\%$ \\
$\leq 25$ years & 25 & 50.0 \\
26-35 years & 07 & 14.0 \\
>35 years & 18 & 36.0 \\
Gender & & \\
Male & 13 & 26.0 \\
Female & 37 & 74.0 \\
Educationalstatus & & \\
Diploma, HSC and below & 33 & 66.0 \\
Graduate & 10 & 20.0 \\
Masters/Post graduate & 7 & 14.0 \\
Monthly Family Income & & \\
$\leq 20000$ taka & 27 & 54.0 \\
20001-40000 taka & 20 & 40.0 \\
$\geq 40001$ taka & 3 & 6.0 \\
\hline
\end{tabular}

Table 2. Opinion about administrative services by the service receiver $(\mathbf{n}=50)$.

\begin{tabular}{llc}
\hline Administrative service & \multicolumn{1}{c}{ Service Receiver $(\mathbf{n}=\mathbf{5 0})$} \\
\hline & $\mathrm{n}$ & $\%$ \\
Visibility of citizen charter & 38 & 78.0 \\
Yes & 12 & 24.0 \\
No & & \\
Visibility of mission and vision of the hospital & 38 & 76.0 \\
Yes & 12 & 24.0 \\
No & & \\
Easy access of the hospital reception & 45 & 90.0 \\
Yes & 5 & 10.0 \\
No & & 40.0 \\
Opinion about problem during registration & 20 & 60.0 \\
Yes & 30 & \\
No & & \\
\hline
\end{tabular}

Table 3. Opinion about clinical services by the service receiver $(n=50)$.

\begin{tabular}{lcc}
\hline Clinical Services & \multicolumn{1}{c}{ Service Receiver $(\mathbf{n}=\mathbf{5 0})$} \\
\hline & $\mathrm{n}$ & $\%$ \\
Waiting time for doctor visit & 10 & 20.0 \\
$<15$ minutes & 25 & 50.0 \\
15-30 minutes & 15 & 30.0 \\
$>30$ minutes & & \\
Doctor concentration to patient & 30 & 60.0 \\
Yes & 20 & 40.0 \\
No & & 68.0 \\
Perform physical examination & 34 & 32.0 \\
Yes & 16 & \\
No & & 90.0 \\
Explanation of prescribed drug use & 45 & 10.0 \\
Yes & 5 & \\
No & & \\
\hline
\end{tabular}

In this study, half $(50.0 \%)$ of the respondents stated that they were waiting for $15-30$ minutes, $60.0 \%$ patients stated that the doctor had concentrated to patients during treatment and more than two-third $(68.0 \%)$ of them performed physical examination. A vast majority (90.0\%) of the patients said that the doctor gave the explanation of prescribed drug (Table 3). Figure 1 depicts the nursing services of the 5S-KAIZEN implemented hospitals. More than three-fourth $(76.0 \%)$ of the respondents replied that they were satisfied on receiving the nursing services and rest of them $(24.0 \%)$ were not satisfied (Figure 1). 
The present study findings stated that less than two-third (64.0\%) of the respondents believed that safety and security system was very good. On the other hand, $64.0 \%$ of the respondents were satisfied about cleanliness of the hospital and $88.0 \%$ had satisfied about ambulance service. Maximum of the respondents $(88.0 \%)$ were satisfied on water and sanitation facility and more than half $(54.0 \%)$ of the respondents were satisfied on electricity supplies in the hospital (Table 4). In this study, a vast majority (88.0\%) of the respondents were satisfied on lab investigation facilities in the hospital. Whereas about $72.0 \%$ and $54.0 \%$ of the respondents were satisfied on drug supply and radiology and imaging services, respectively (Figure 2).

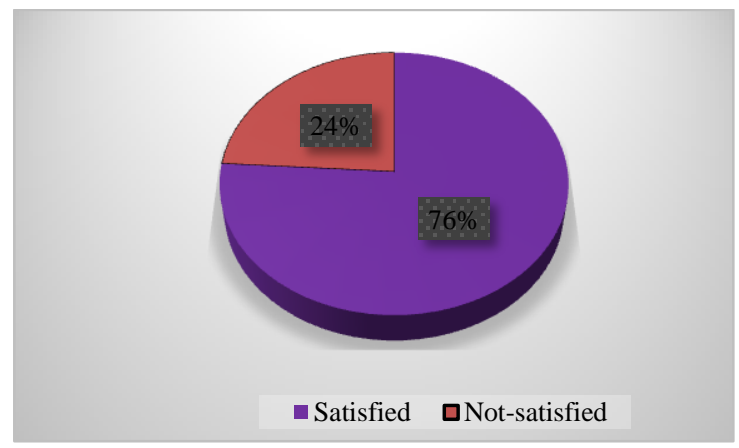

Figure 1. Opinion about nursing services by the service receiver $(n=50)$.

Table 4. Opinion about utility services by the service receiver $(n=50)$.

\begin{tabular}{llc}
\hline Utility Services & \multicolumn{1}{c}{ Service Receiver $(\mathbf{n}=\mathbf{5 0})$} \\
\hline & $\mathrm{n}$ & $\%$ \\
Safety and security of the hospital & 32 & 64.0 \\
Very good & 14 & 28.0 \\
Good & 4 & 8.0 \\
Bad & & \\
Cleanliness of the hospital & 32 & 64.0 \\
Satisfactory & 18 & 36.0 \\
Not-satisfactory & & \\
Ambulance service & 44 & 88.0 \\
Yes & 6 & 12.0 \\
No & & 82.0 \\
Adequate water and sanitation facility & 41 & 18.0 \\
Satisfactory & 9 & 54.0 \\
Not-satisfactory & & 46.0 \\
Electricity supply & 27 & \\
Satisfactory & 23 & \\
Not-satisfactory & & \\
\hline
\end{tabular}

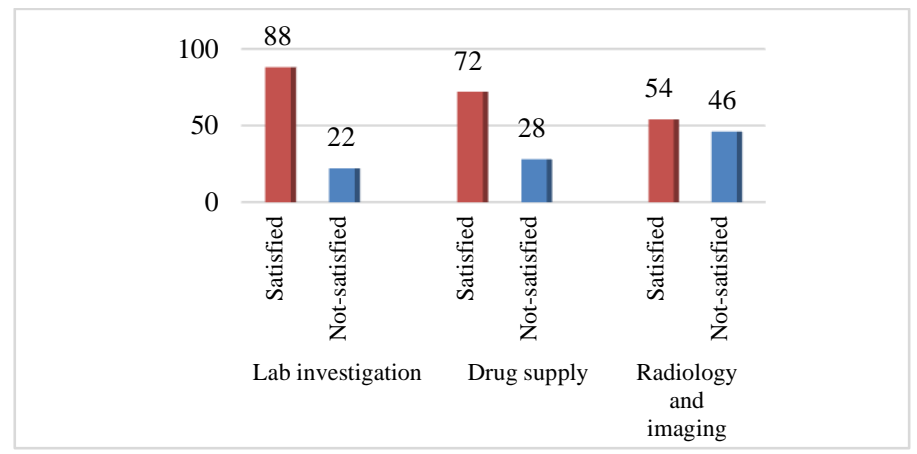

Figure 2. Opinion about support services by the service receiver $(\mathbf{n}=50)$.

\section{Discussion}

This study was undertaken to find out the quality of hospital services in 5S-KAIZEN-TQM implemented 100 bedded district hospital. The current study shows that about half $(50.0 \%)$ of the service receiver was $\leq 25$ years 
in which maximum (74.0\%) were female. A cross-sectional comparative study conducted by Gapp et al., 2008 found that $67.8 \%$ of the respondents were female. There is a similarity with the present study findings and these may be due to the similar characteristics of the study respondents.

In the present study, $78.0 \%$ respondents stated that they saw citizen charter in the 5S-KAIZEN-TQM implemented hospital. This finding is inconsistent with the study conducted by Emad and Al-shdaifat in the year 2015. In our study it was revealed that $50.0 \%$ of the respondents were waiting for $15-30$ minutes to visit the doctor whereas $60.0 \%$ patients stated that the doctor had concentrated to patients during treatment and more than two-third $(68.0 \%)$ of them performed physical examination. More than three-fourth $(76.0 \%)$ of the respondents replied that they were satisfied on receiving the nursing services and rest of them $(24.0 \%)$ were not satisfied.

Asian countries like Bangladesh often fight with inadequate human resource, shortage of supplies along with the inadequate access to necessary medicines and technologies which resulted a compromise with the quality of care (Salam et al., 2014; Islam et al., 2015; Chowdhury et al., 2009). However, many of the Asian countries addressed the quality issues by adopting the 5S-KAIZEN-TQM approaches successfully (Islam et al., 2015; Bhuiyan and Baghel, 2005). Not only the Asian countries but also the African countries experienced different types of approaches of quality programs to improve quality of health facility care (Samky et al., 2012 and Titu et al., 2010).

The present study revealed that less than two-third (64.0\%) of the respondents believed that safety and security system was very good. Maximum of the respondents (88.0\%) were satisfied on water and sanitation facility and more than half $(54.0 \%)$ of the respondents were satisfied on electricity supplies in the hospital. Additionally, in a study conducted by Mmbando, 2012 and reported that 5S-CQI-TQM was first implemented at Kilema hospital in October 2011 and the immediate quality improvement outcome and impact was observed six months later at 4 areas practicing 5S: Maternity ward, Pharmacy, Operating Theatre and Laboratory (Mmbando, 2012).

The results from this study show a set of key success factors for KAIZEN implementation in the public service sector, which are government commitment and support, top management commitment and involvement, visionary leadership, customer focus, good coordination and establishment of cultural change programmes embracing employee empowerment and involvement throughout the entire KAIZEN implementation process.

\section{Conclusions}

5S-KAIZEN-TQM could be applied to health-care facilities regardless of locations in Bangladesh. The low-cost nature of $5 \mathrm{~S}$ implies that this method is an appropriate initial step toward quality improvement even among resource-constrained healthcare facilities. However, the evidence base on its applicability in such settings is limited, and further research is required in this area. In addition to understand its applicability in the context of strengthening health systems in Bangladesh, the cost-effectiveness, viable scale-up mechanisms, and sustainability of $5 \mathrm{~S}$ application also need to be further studied.

\section{Acknowledgement}

We are grateful to the hospital authority for the permission to conduct the study. We would like to thank all the study participants who added an extensive contribution during data collection.

\section{Conflict of interest}

None to declare.

\section{References}

Bhuiyan N and A Baghel, 2005. An overview of continuous improvement: from the past to the present. Management Decision., 43: 761-771.

Chalice R, 2007. Improving healthcare using Toyota lean production methods: 46 steps for improvement. Milwaukee: ASQ Quality Press.

Chowdhury S, SA Hossain and A Halim, 2009. Assessment of quality of care in maternal and newborn health services available in public health care facilities in Bangladesh. Bangladesh Med. Res. Counc. Bull., 35: 5356.

Emad A and Al-shdaifat, 2015. Implementation of Total Quality management in Hospital. Journal of Taibah University Medical Sciences, 10: 461-466.

Gapp R, R Fisher and K Kobayashi, 2008. Implementing 5S within a Japanese context: an integrated management system. Manage Decis., 46: 565-79. 
Graban M, 2011. Lean hospitals: improving quality, patient safety, and employee engagement. Boca Raton: CRC Press.

Hasegawa T, 2006. A study on organizational reinforcement through total quality management in the health and medical care sector. Tokyo: JICA Institute for International Cooperation.

Hirano H, 1995. Pillars of the visual workplace. Portland: Productivity, Inc.

Hirano H, 1996.5S for operators: 5 pillars of the visual workplace. Portland, OR: Productivity Press.

Honda S, 2012. Inspired by Sri-Lankan practice: scaling-up 5S-KAIZEN-TQM for improving African hospital service. In: JICA Research Institute, editor. Scaling up South-South and triangular cooperation. Tokyo: JICA Research Institute,:107-27Imai M. Gemba Kaizen: a commonsense approach to a continuous improvement strategy. New York: McGraw Hill.

Islam F, A Rahman, A Halim, C Eriksson and F Rahman, 2015. Perceptions of health care providers and patients on quality of care in maternal and neonatal health in fourteen Bangladesh government healthcare facilities: a mixed-method study. BMC Health Services Research, 15: 237.

Japan International Cooperation Agency (JICA), 2013. JICA's operation in health sector-present and future. Tokyo: JICA.

Kaplan GS, 2008. Advanced lean thinking: proven methods to reduce waste and improve quality in health care. Oakbrook Terrace: Joint Commission Resources.

Mazzocato P, C Savage, M Brommels, H Aronsson and J Thor, 2010. Lean thinking in healthcare: a realist review of the literature. Qual Saf Health Care., 19: 376-382.

Ministry of Health and Social Welfare (MHSW), 2009. Implementation guideline for 5S-CQI-TQM approaches in Tanzania: Foundation of all Quality Improvement Programme. Dar es Salaam: The United Republic of Tanzania.

Mmbando C, 2012. Evaluation of the 5S Philosophy at Kilema Designated District Hospital. Kilema Designated District Hospital.

Powell AE, RK Rushmer and HTO Davies, 2008. A systematic narrative review of quality improvement models in health care (in support of NHS Quality Improvement Scotland). Social Dimensions of Health Institute at the Universities of Dundee and St Andrews.

Salam RA, ZS Lassi, JK Das and ZA Bhutta, 2014. Evidence from district level inputs to improve quality of care for maternal and newborn health: interventions and findings. Reproductive Health., 11: S3.

Samky E, H Kiwelu, H Ishijima and R Dibogo, 2012. Improve Revenue Collection with KAIZEN Approach in Public Hospital. Mbeya Consultation Hospital, Japan International Cooperation Agency.

Takahara A, 2010. Clinical 5S for healthcare. Bellingham: Enna Products Corporation.

Titu MA, C Oprean and D Grecu, 2010. Applying the KAIZEN Method and the 5S Technique in the Activity of Post-Sale Services in the Knowledge-Based Organization. Proceedings of the International Multi-Conference of Engineers and Computer Scientists, III. Hong Kong.

Womack J, D Jones and D Roos, 1990. The machine that changed the world. New York: Rawson Associates. 